\title{
A Review of Internet of Things Technologies for Ambient Assisted Living Environments
}

\author{
Rytis Maskeliūnas ${ }^{1}\left(\mathbb{0}\right.$, Robertas Damaševičius $^{1, *}{ }^{\mathbb{D}}$ and Sagiv Segal ${ }^{2}$ \\ 1 Faculty of Applied Mathematics, Silesian University of Technology, Kaszubska 23, 44-100 Gliwice, Poland; \\ rytis.maskeliunas@polsl.pl \\ 2 R.S Research Solutions LTD, 13 Carmel St. 7630513 Rehovot, Israel; sagivs@grantinfo.org \\ * Correspondence: robertas.damasevicius@polsl.pl
}

Received: 23 October 2019; Accepted: 11 December 2019; Published: 12 December 2019

\begin{abstract}
The internet of things (IoT) aims to extend the internet to real-world objects, connecting smart and sensing devices into a global network infrastructure by connecting physical and virtual objects. The IoT has the potential to increase the quality of life of inhabitants and users of intelligent ambient assisted living (AAL) environments. The paper overviews and discusses the IoT technologies and their foreseen impacts and challenges for the AAL domain. The results of this review are summarized as the IoT based gerontechnology acceptance model for the assisted living domain. The model focuses on the acceptance of new technologies by older people and underscores the need for the adoption of the IoT for the AAL domain.
\end{abstract}

Keywords: internet of things; smart homes; smart environments; ambient assisted living; gerontechnology; technology acceptance model

\section{Introduction}

The rise of the popularity of the internet of things (IoT) throughout the world has been steadily increasing in recent years. The IoT is regarded not only for its state-of-the-art approach to research, but also for its practicality in many domains, illustrating high demand and applicability in multiple fields. This is largely because the IoT has radically changed the business processes in many sectors, where one key mechanism has been the convergence of traditional information and communication technologies (ICT), linked with real-time processing opportunities provided by Big Data and IoT. One of the most significant investments, which have been focused upon is more of a modern, evolutionary approach to IoT, which in this case, refers to the establishment and growth of future IoT ecosystems [1].

A widely used definition of the IoT provided by Gigli and Koo [2] is "the current tendency for unifying all the resources in our world under a common infrastructure". This common infrastructure provided by the IoT evidently provides many potential benefits for businesses, individuals and scientific researchers. The IoT technologies are considered as enablers of the next industrial revolution [3] and future healthcare [4]. IoT relies not only on strong infrastructure, but also on its design principles as a driving force in innovation and lesser constrained boundary conditions for creating the IoT ecosystems. Neither estimate can deny the value of IoT working in the industry in a multi-platform role and its potential in increasing global economic growth. These trends are best illustrated with the Gartner hype cycle for emerging technologies [5]. This famous emerging technology prediction gives a clear indication of the importance and the innovation potential of different IoT technologies.

Cognitive computing refers to smart systems that naturally interact with humans and other smart systems [6]. The essential technologies supporting smart system functionality are IoT for networking, artificial intelligence (AI) for data analytics and cloud computing for data services [7]. Here AI refers to methods that enable the performance of tasks, which otherwise would require the use of human 
intelligence, such as decision-making. IoT specifically focuses on the technologies that bridge the physical world ("things"), digital technologies and the social world (social behavior, etc.), based on computer vision, speech and natural language processing for natural human-computer interaction, smart allocation of resource, and intelligent provision of services [8]. The IoT technologies for AAL are technologies which focus on the improving wellbeing and increasing quality of life of its users. Currently, the IoT platforms, as well as research on connected smart home and cognitive computing are in the phase of peak of inflated expectations. These trends show that there is a tremendous potential for innovation and growth where IoT technologies are concerned, which is in a full alignment with the actual worldwide trends both within the research community as well as within industrial settings, thus providing a great potential for the assisted living and healthy aging solutions as well.

An ambient assisted living (AAL) environment is an integration of stand-alone assistive technologies, solutions and services [9]. AAL (or simply assisted living) solutions can provide positive influence on health and quality of life of people, especially the older people ones. The IoT technologies used for AAL can address major care problems amongst the elderly population [10] such as: (1) limitations in activities of daily living, (2) risk of fall, (3) chronic diseases, (4) dementia, (5) depressive disorders, (6) social divide, (7) poor medication management, and (8) poor state of well-being. The needs of older people can be solved by adopting the appropriate IoT technological solutions [11] and global services specifically targeting older people [12], such as location-based services to support freedom of movement and greater independence [13].

Modern assistive technologies (or gerontechnologies [14,15], in case of assistive technologies used for improving wellbeing of for older people) constitute a wide range of technological solutions aimed at improving well-being of older people [16] (Figure 1). These technologies are used for personalized medicine, smart health, health tracking, telehealth, health-as-a-service (HaaS), smart drugs and multiple other applications.

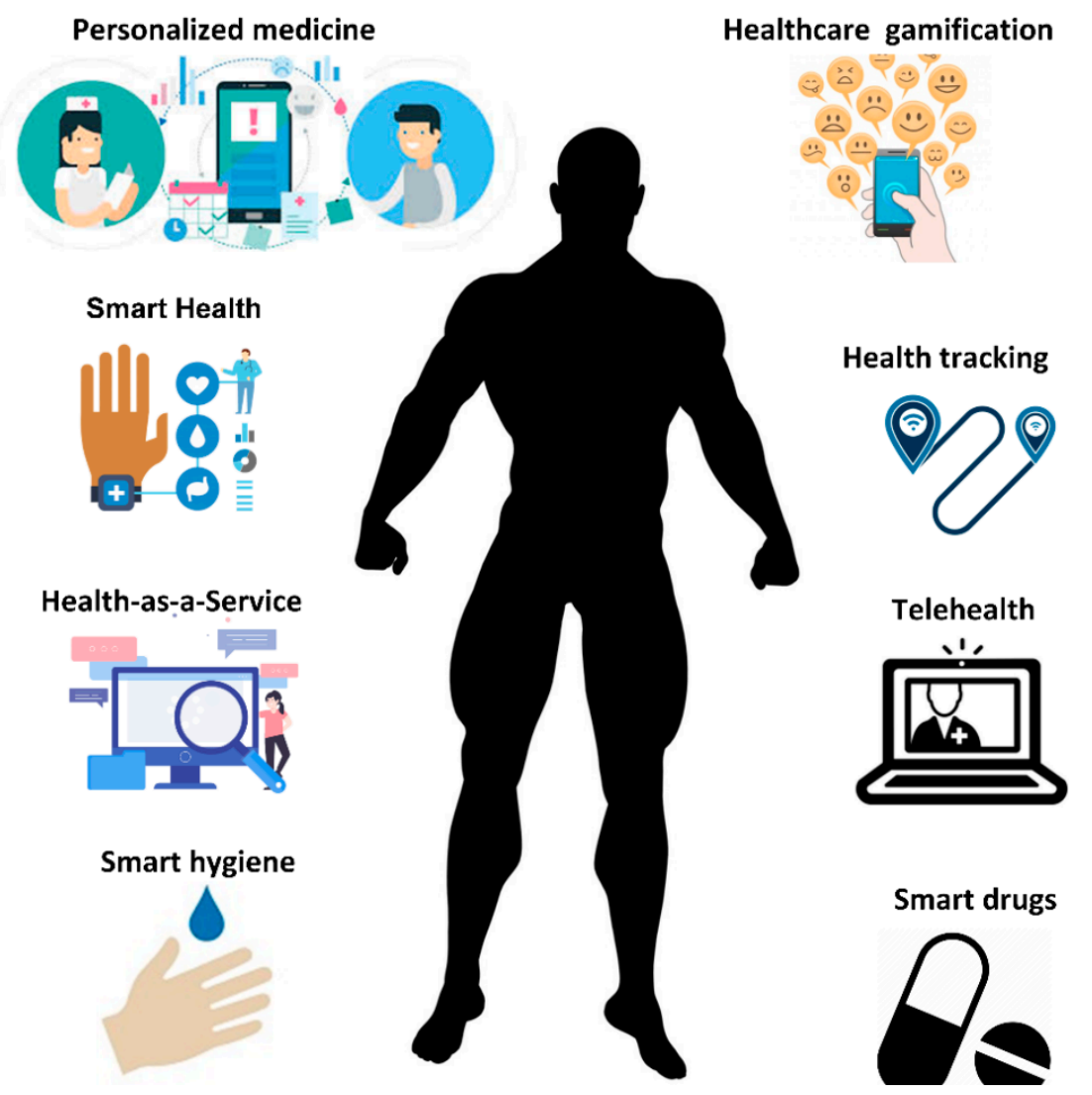

Figure 1. Applications of internet of things (IoT) technologies for the ambient assisted living (AAL) domain. 
Since one of the most relevant challenges is to enable older people to live as much as possible independently at home, it is crucial to investigate how gerontechnologies could support them in the context of home environment. Different types of assistive technologies, information technology (IT) and ICT, are developed and mixed for newer and more complex and comprehensive solutions. In general terms, there are the following research areas of gerontechnologies:

- Social inclusion and communication: technologies that aim to enable older people to communicate and interact with others, like family members and friends, in order to maintain their social life and thus improve their well-being [17];

- Psychosocial factors of human-technology interaction and usage: some socio-economic and psychological aspects are relevant for understanding how different profiles of older people interact with and use technologies [18];

- Telemedicine, telehealth and telecare: in order to enable a continuous monitoring of eventual health problems and long-term conditions, typical of older age, remote services offered by healthcare organizations could widen the possibility for older people to access appropriate care and thus improve their health status and clinical outcomes [19];

- $\quad$ Entertainment and media: serious games and smart objects at home could facilitate the daily living of older people by enabling alternative commands for home management or being engaged in proper physical or mental training [20,21];

- Sensing and interacting: sensors installed at home represent a great opportunity for the monitoring of older people's activities and behaviors, as well as the detection of sudden risks or accidents [22]. Such information, when appropriately treated, could be notified to eventual family caregivers or care services for immediate intervention when a problem occurs.

The previous surveys on the IoT primarily focused on discussing the evolution of IoT across different domains of application [3], or specifically focused on the applications in the healthcare domain [4]. Other surveys focused on opportunities and limitations of current IoT healthcare systems, and frameworks in the context of fog computing [23-25]; discuss current implementations for home-based tele-monitoring and smart home technologies that support healthy aging [26]; review applications, services and security and privacy issues of IoT in healthcare frameworks and systems [27]; introduce a systematic IoT in e-health ecosystem, discuss security issues in IoT devices and networks, and consider challenges and future directions for IoT in e-health [28]; discuss smart homes, including medical sensors, actuators and ICT, which enable continuous tele-monitoring of older people's health and wellbeing [29]; overview different types of sensors and communications methods in various IoT systems in healthcare applications [30]; analyze the role of cloud-based computing for critical IoT systems in healthcare [31].

The aim this paper is to present the comprehensive overview of the challenges raised and solutions provided by IoT technology to the domain of AAL systems and assistive technologies. Approaches on IoT technologies reviewed in this paper are also often found in cognitive areas, in their respectful application of general human-machine interactions, machine learning, computer vision, speech and natural language processing.

The structure of this paper is as follows: We describe the methods used and research questions raised in Section 2. We review the state of the art of IoT technologies for AAL in Section 3. We discuss the acceptance of new technologies for assisted living and propose the technology acceptance model (TAM) of IoT based gerontechnology for the assistive living domain in Section 4. We present a discussion on the situations, needs and challenges of IoT technologies and their applications in Section 5. Finally, we present conclusions in Section 6.

\section{Methods}

In the review process, we followed the guidelines of a systematic literature review [32] regarding the methodologies for performing systematic literature reviews and mapping studies. The main 
aim was to identify gaps and research trends in the domain by formulating appropriate research questions, and then identifying and assessing the related research papers. In identifying the review scope, research questions and search terms, we followed the suggestions of the PICOC (Population, Intervention, Comparison, Outcomes and Context) model [33].

\subsection{Research Questions}

We formulated the following main research questions (RQs):

RQ1. How machine learning and intelligent decision making and control are used in IoT based AAL systems?

RQ2. How IoT integration technologies and platforms are employed for AAL solutions?

RQ3. What methodologies and tools are used for multi-agent based intellectual applications for assisted living?

RQ4. How cognitive and affective IoT is adopted for IoT based AAL systems?

RQ5. What are the needs to consider psychosocial factors of human-technology interaction, communication and usage?

RQ6. How localization, tracking and activity detection technologies are integrated into IoT based AAL systems?

\subsection{Search Query}

Constructing the search query is one of the main challenges when conducting a review. In order to provide an answer to the analyzed research questions, a review must acquire all possible results that are associated with the domain of interest. With that aim in mind, the employed search string must contain key terms related to that topic, so that the obtained results are relevant.

The literature for our review was selected by searching the Clarivate Analytics Web of Science and Scopus (Elsevier) scientific databases for articles on the use of IoT in the AAL domain over the period of 2011-2019, and selecting the relevant articles according to the titles and abstracts. The search query was composed of the following terms:

Internet of Things AND (Assisted OR Assistive)

\subsection{Inclusion and Exclusion Criteria}

The selected articles were studied according to the quality and relevance of the research topic and their literature references were evaluated for possible inclusion in this review. The inclusion criteria were studies that included smart homes, smart environments, AAL systems and platforms oriented at tele-monitoring or support complex needs (both physical and mental) of older people. The exclusion criteria were studies published in lower quality outlets (conference papers and proceedings) or without a proper peer review process (book chapters, Ph.D. dissertations or Masters' theses), different types of literature reviews (including surveys, meta-analyses and tertiary studies), purely theoretical papers, research studies unrelated to supporting healthy aging or older people (such as home systems for ensuring security), studies on assistive devices (such as canes for visually impaired people), those which were not a part of larger-scale computing or networking infrastructure, studies with only an abstract available, articles published before 2011 and non-English publications.

After the exclusion of irrelevant articles, the data from 246 relevant articles were extracted from the original search results. The selection process is illustrated as a Preferred Reporting Items for Systematic Reviews and Meta-Analyses (PRISMA) [34] flow diagram in Figure 2.

The quality of the process was ensured by including two raters to perform the selection for relevant articles, while a third rater was enrolled in case of disagreement. This helped us to apply the inclusion and exclusion criteria, despite their subjective formulation. 


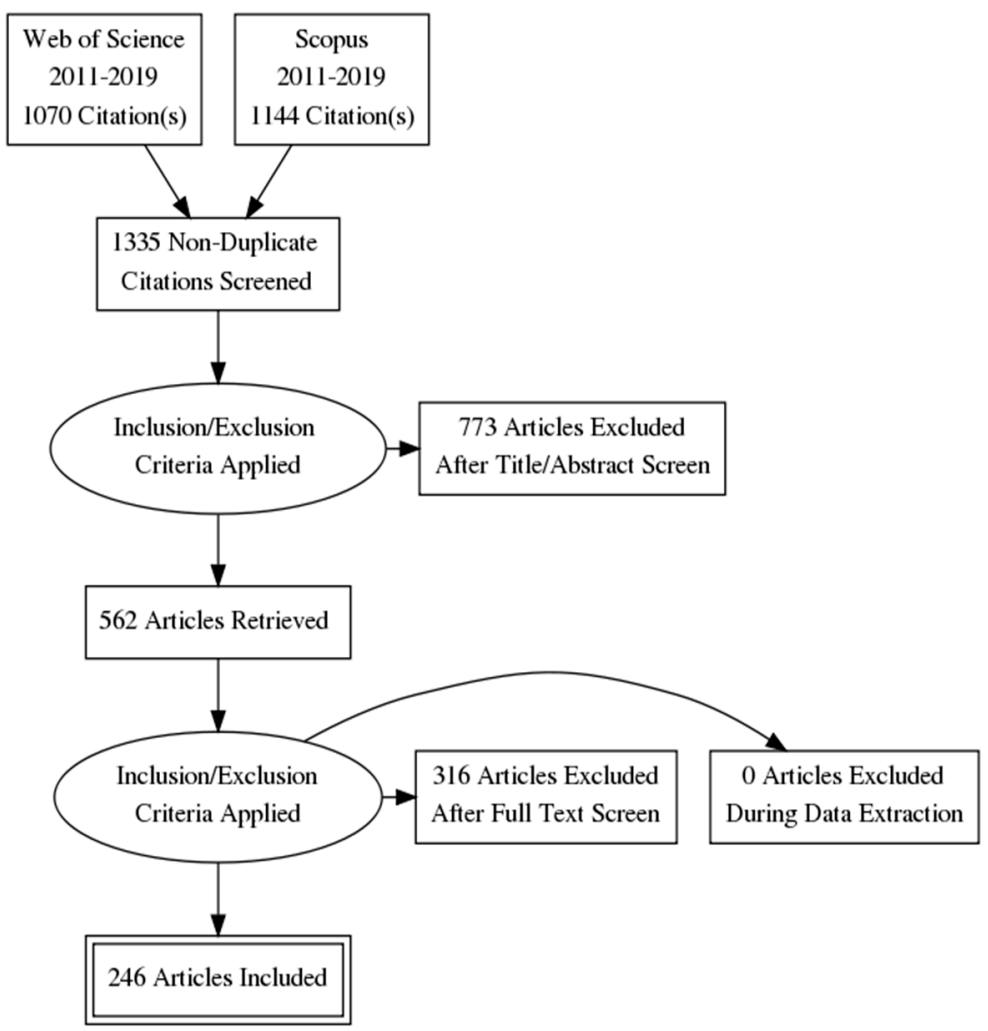

Figure 2. PRISMA [34] flow diagram of paper selection process.

\subsection{Search Outputs and Results}

The statistical characteristics of the identified articles were as follows: the number of citations of selected articles had a mean of 11.3 and the h-index of 18. After removing articles with zero citations, the remaining articles had a mean of 16.76 citations. The mean number of years since article publication aws 4.20 for all the selected. Most of the publications fell into the topics of engineering electrical electronic (37) and computer science information systems (35).

The results of the search (found) papers in Web of Science and Scopus databases (see Figure 3) indicate the continuous growth of interest in this topic of research.

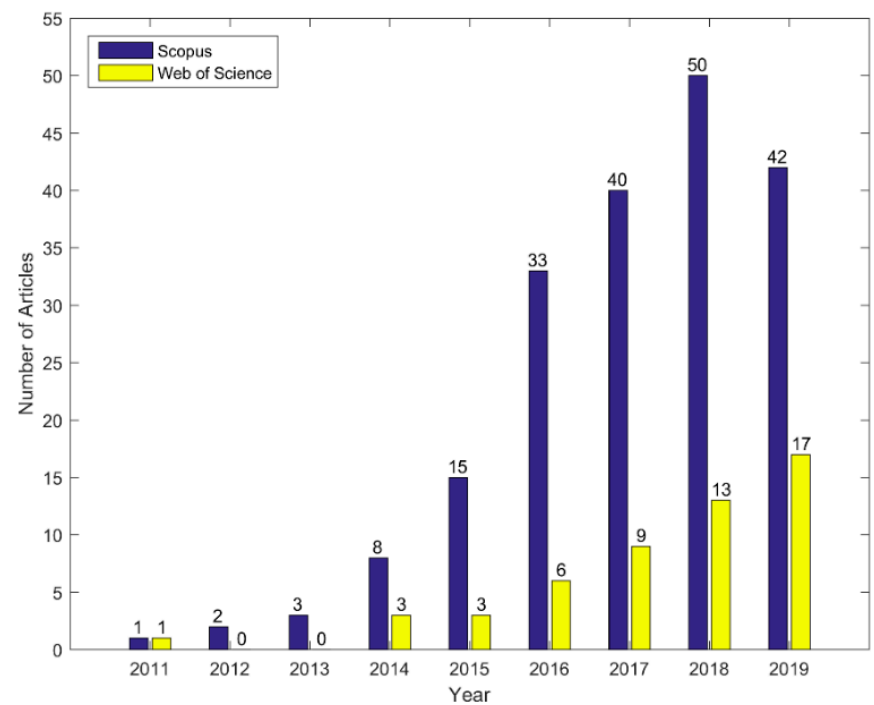

Figure 3. Number of research papers on IoT for AAL published between 2011 and 2019 (according to Scopus and Web of Science data). 
The analysis of solutions and applications provided by IoT technologies is summarized in Figure 4. In summarizing the applications, we follow the taxonomy of AAL systems presented in [35]. The taxonomy [35] identifies specific health monitoring systems, telepresence, ADL assistance, mobility assistance (positioning or localization), specific interfaces, virtual reality, wandering prevention systems, smart home systems, intelligent devices, fall detection systems, home automation, and robotic companions. The analysis shows that interest in these research subtopics has been growing steadily with a majority of research papers dedicated to developing or using different kinds of sensors, smart devices, smart home systems and health monitoring.

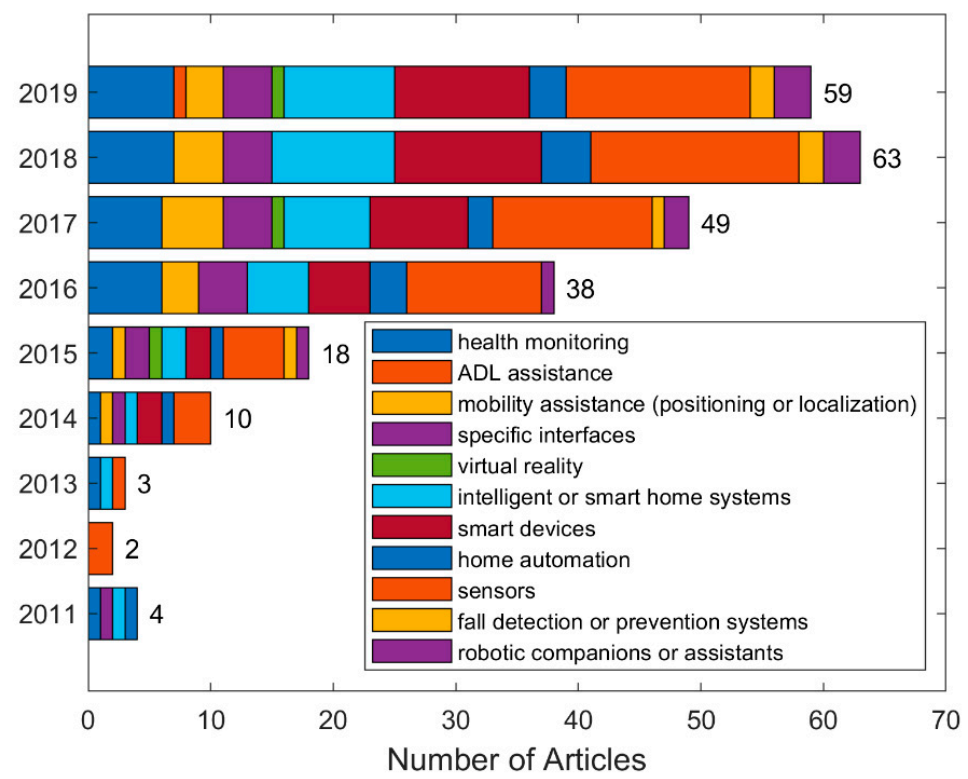

(a)

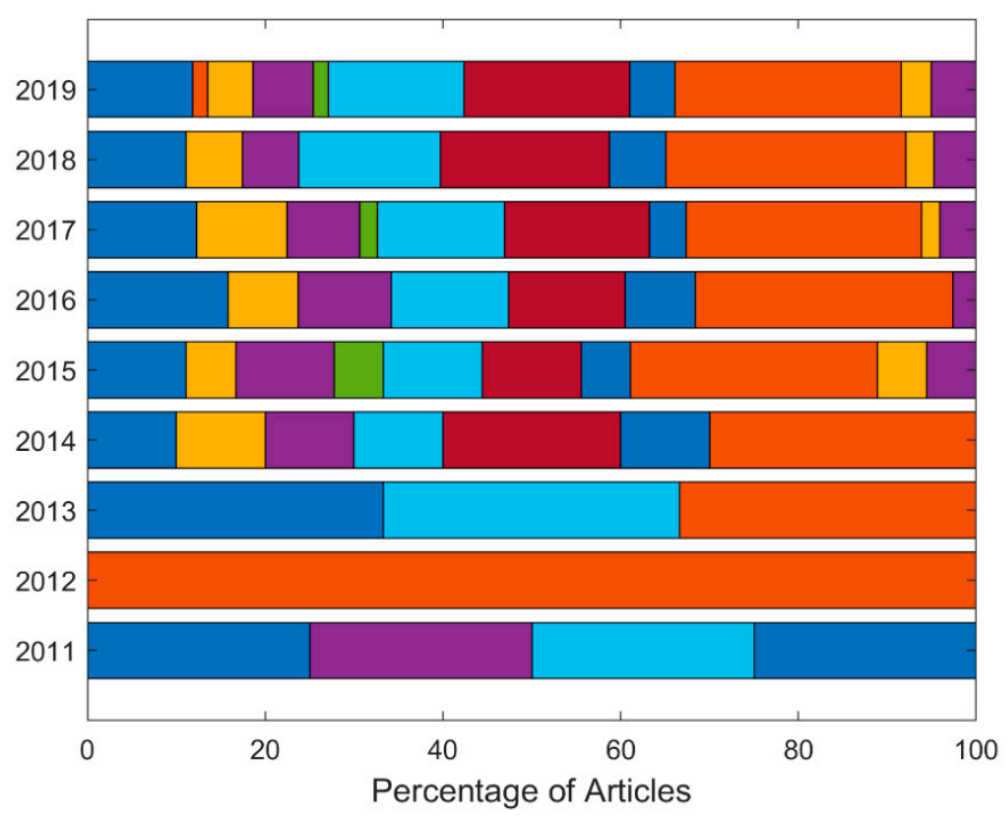

(b)

Figure 4. Summary of solutions for older people addressed by IoT systems. (a) Number of papers published in 2011-2019. (b) Percentage of papers published in 2011-2019. The list of problems follows a taxonomy of AAL systems outlined in [35]. Note that some papers have overlapping topics. 


\section{State of the Art in IoT Technologies for Ambient Assistive Living}

\subsection{IoT Technologies for Ambient Assistive Living}

The IoT technologies for AAL domain include research areas, specific to IoT, but not limited to: smart homes and smart environments; ambient assisted living (AAL); agent-based pervasive computing and decision-making methods; and IoT sensing technologies (wireless sensor networks, smart sensors, gateways, etc.).

There are many scientific publications in the abovementioned fields, presenting various state-of-the-art technologies, methods and systems, which are intended to create smart environments at homes or cities, providing various services and automation features, to improve the life, work and leisure conditions of the inhabitants of those spaces. Many papers propose various IoT and smart systems' architectures [36], which connect intelligent personal assistants, cloud computing and smart environment paradigms, concentrating on the creation of connected smart living environments for the older people or disabled people. As presented in [37-40], the AAL research area includes many subtopics like user-oriented services, adaptive user interfaces, data collection, wearables, human activity recognition and indoor localization, behavior monitoring, etc. On the other hand, the review [41] shows that until now the AAL domain misses the existing IoT ecosystems.

A very important part of the cognitive methods and solutions is related to smart homes, smart environments and smart services, based on IoT. Usually this includes home/environment appliances control, as in [42,43], or the modeling and creation of smart buildings [44]. In order to provide personalized services and control automation, there are several methods proposed which allow us to detect humans in IoT environments as presented in [45], where the Bluetooth Wireless Sensor Network (WSN) is used as a communication platform for human identification using unobtrusive sensors. The control and adjustment of such smart AAL environments are usually based on the mobile terminals and wearable IoT devices as in [46]. Some researchers are even trying to employ (though still not very successfully) emotion recognition for the smart home and AAL applications [47].

A very important aspect of smart living related research area is IoT security. This emerging area is very important, since many IoT devices and services have only basic security or does not have it at all. Although, the researchers are trying to improve situation proposing various methods and countermeasures (as seen in [48,49]), the IoT security standards are still under development and various companies offer their own proprietary solutions, which do not cover all security fields.

As mentioned above, the concept of cognitive technologies for smart environments goes far beyond the home environment and covers smart cities and public IoT services. For example, IoT has started to be used for entertainment and education such as the intelligent cultural spaces presented in [50] or the IoT-aware services for smart museums [51], based on an indoor localization method (using Bluetooth), wearable devices and the users' mobile devices to display and share cultural contents in the cloud. Smart parking system [52], blind navigation system [53], dangerous situations detection system [54] or activity prediction system for mobile services [55] are also good examples of the IoT AAL applications in the context of smart cities and connected smart environments.

\subsection{Challenges in Application of IoT Technologies for $A A L$}

Although there are many scientific efforts in the IoT-based AAL related fields, there are still many challenges and issues, related with:

- Intelligence. Most of the research papers talk about smart systems and environments, while the real intelligence means not only simple automation according to the pre-defined rules (smart behavior), but rather learning, adaptation, prediction and decision making based on the AI methods, according to the habits and behavior of the users of the intelligent environment as well as changes in that environment. Intelligent system for older people health monitoring (such as the one described in [56]), in order to provide highest level of comfort, energy savings or principally new services, needs to: constantly monitor the environment and its inhabitants, learn from their 
behavior, update its rules, predict the future changes and events, control environment and provide services for the users without intervention from the latter's. Current methods allow this partially, but still lack precision, fault tolerance, unobtrusiveness and stability.

- IoT security. Since there are no common widely accepted IoT security standards [57], many IoT producers propose to use their own proprietary security solutions, while many IoT security fields are still uncovered, e.g., home and industrial automation devices usually have no security technologies, completely relying on the central gateway security (if such is present). The recent world-wide cyber-attacks used IoT malwares and botnets as well, completely proving, how vulnerable IoT and its infrastructure is [58,59]. From the security perspective, IoT is more threat bringing $[60,61]$ rather than security enabling technology. Although many of the potential advantages are still in the concept phase, it is necessary to mention them:

- Introduction of collaborative IoT networks [62] could lead to a more resistive (against cyberattacks) design;

- Evaluation of security requirements on the design phase, reviewing the currently existing process of IoT development to the embedded security approach [63] can significantly decrease the number of potential IoT related threats;

- End-to-end encryption [64] could be a method for insuring trust in communication between IoT entities;

- $\quad$ Lightweight security solutions [65-67] that could cover security needs and act on limited IoT resources.

- Integration. There is a huge variety of IoT devices, which cannot be interconnected at all or can be connected only at low level (usually network) demanding special integration solutions and additional development. As with IoT security, there is a lack of common integration and interoperability standards, especially for the dynamic discovery and plug-and-play support of IoT devices [68,69].

- Unobtrusive sensing technologies and their precision. Though there are a lot of methods for indoor localization, posture detection, bio-parameters and environment monitoring, they still lack precision and require many obtrusive or even invasive sensors, which in turn is a very uncomfortable and expensive way to create the AAL environments [70].

\subsection{Outlook}

There are several international initiatives created to identify the IoT technology research challenges. One example is the European Research Cluster on Internet of Things (IERC), which is an umbrella for the ongoing exchange of ideas and cooperation between European and international experts. There are also several surveys and technology trend forecasts, which try to define the direction of future research areas [71]. Though there are many scientific efforts in the IoT-based ambient assistive living (AAL) [72] related fields, there are still many challenges and issues, related with intelligence and decision-making, IoT integration, unobtrusive sensing technologies and their precision.

The fundamental goal in this area is to significantly advance the fundamental understanding of the newly rising aspects of the applications of IoT technologies in the field of Smart Homes and Smart Environments. The principle research areas of include, but are not restricted to smart homes and smart environments, smart cities, smart buildings, AAL, agent-based pervasive computing and decision-making methods, and IoT sensing technologies, including wireless sensor networks (WSN), smart sensors and gateways.

\section{Acceptance of New Gerontechnologies for Assisted Living}

The technology acceptability models, selected to be compatible with applications for older people to accept and use a technology, starts with the very classical TAM model [73]. TAM explains the user's 
behavior when using ICT can be used to understand the usefulness of technology via the attitudes of the use. The usefulness of TAM comes from understanding users' adoption and use of emerging technologies, which is predicated by the person's perceptions of the benefit from using the technology the and ease of use.

A model depicting various gerontechnology usage factors discussed in [74], including those of multi stakeholder collaboration in older people communities [75] is illustrated in Figure 5.

Judging from a literature reviewed (e.g., see [76]), we can establish that the acceptance of the IoT based gerontechnology within older people users is largely dependent on the following elements. First, the older people users must already have some motivation (as cognitive state and physical condition often are the limiting interaction factors) and perception of the added value.

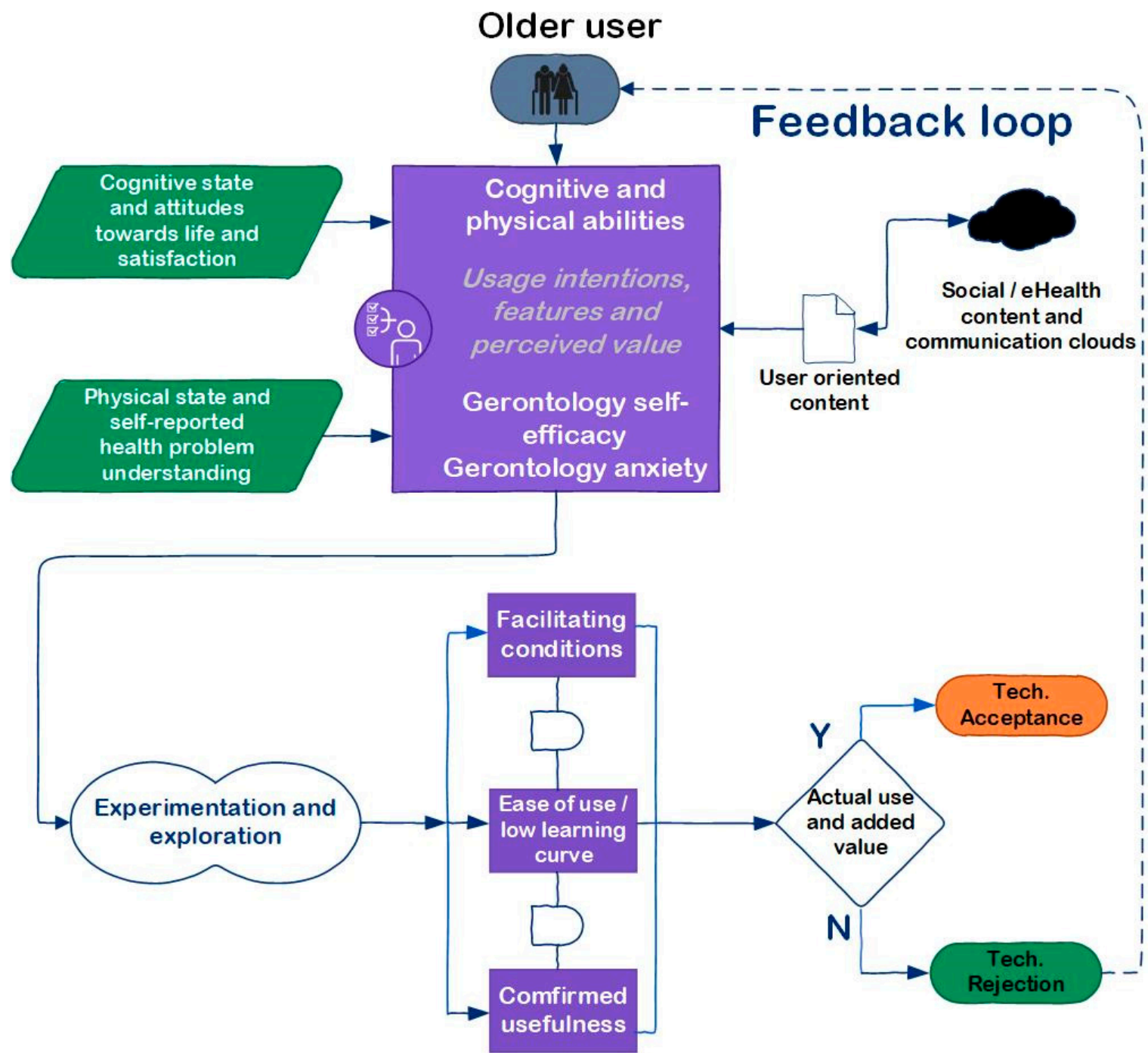

Figure 5. Suggested technology acceptance model of IoT based gerontechnologies for AAL.

Motivation greatly influences the extent to which older people use their experiential and deliberative skills to make the technology-related decisions [77]. However, motivation often has a personal dimension, i.e., unless the tasks are personally relevant, older people will tend to minimize their cognitive effort. Today, motivation often comes from the social perspective, starting from easy communication with relatives and grandchildren, social network features, social, online, entertaining content and finishing with health-related telecare solutions.

In the 21st century, the elderly population often bravely start experimenting with and embracing the new (although sometimes only for themselves) technology. Depending on the facilitating conditions 
and the ease of use (little to no learning curve) and confirmed usefulness, the older end-users often come to the evaluation of benefit, and if they genuinely see the device useful, they embrace it and start accepting it into their daily lives. Social networks and virtual communities can help older people to support an interest and a positive feedback among the older AAL users as well as to bridge the digital divide between older people and the younger generations [78]. Therefore, the proposed model envisions a possible feedback gathered from the rejected technology solutions.

Considering the active aging paradigm, it is essential to develop and implement new strategies and technologies, even if typical barriers, such as lack of experience (or even fear) of modern technology in general, and the gerontology self-efficacy and anxiety, in addition to age and cognitive abilities. In this regard, we can hypothesize that a familiar environment, like a home of the elderly user, can become intelligent and provide various forms of monitoring, from localization and fall detection to non-intrusive healthcare, services, which are vital for our target audiences. Current technology allows customization to the user preferences and takes less strain on environment (smart systems lead to less consumption). The acceptance model is based on the claim, that IoT can serve as smart eyes, ears and hands assisting our elderly person and capable of providing necessary and needed health at appropriate times and situations. The main facilitating factors can be distinguished like the ease of use, as well as general user familiarity with technology (including fear of technology), possible improvement of care service (very important in digitized e-health services), low technical demands and an option to personalize to each elderly person as often the disabilities (if exists) varies, in addition to living, cultural, economic and environmental factors. Various facilitating conditions, tied with ease of experimentation and acceptable result means that ecosystems based on this principle can also work towards providing new knowledge for building new IoT based assistive services or technically also extending the already supported services, leading to the immediate recognition of added value of the IoT based assistive technologies.

In Table 1, we provide several examples of successful or failed to adopt IoT devices, which were aimed at improving the living conditions of ageing people.

Table 1. Examples of successful/failed products (services) employing IoT technologies of AAL.

\begin{tabular}{|c|c|}
\hline Product/Service & Reason of Success/Failure \\
\hline \multicolumn{2}{|c|}{ Examples of Success } \\
\hline Nest Learning Thermostat (3rd generation) [79] & $\begin{array}{l}\text { Simplicity of use, no need of programming, } \\
\text { self-learning, adaptability, context-awareness }\end{array}$ \\
\hline Flic wireless smart button with TAGhelper [80] & Simplicity, intuitiveness, low learning curve \\
\hline IFTTT applet for remote home lighting control [81] & Ease of use, low learning curve \\
\hline SUUNTO smart chestbelt heart rate sensor [82] & Ease of use, usefulness, high reliability \\
\hline Philips HUE Light Bulbs [83] & Ease of use, usefulness, low learning curve \\
\hline \multicolumn{2}{|c|}{ Examples of Failure } \\
\hline Banknote identifier [84] & Difficult to use, complex user input \\
\hline Prosthetic Damping Control [85] & $\begin{array}{l}\text { Manual control required, low comfortability, high } \\
\text { complexity }\end{array}$ \\
\hline Toto Intelligence Toilet II [86] & Over-complexity, difficult to use \\
\hline Head driven mouse for smartwatch [87] & Low practicality, high learning curve \\
\hline Smart armchair [88] & Low usefulness, complex to adjust and control \\
\hline Home Automation Kit for smart home control [89] & High complexity, difficult to use \\
\hline Smart insoles [90] & Low reliability \\
\hline Garmin Vivofit activity tracker [91] & Low usability, high learning curve \\
\hline
\end{tabular}

Our proposed model is in agreement with similar models and frameworks of adopting technology for healthcare domain such as Anchored, Realistic, Co-Creative, Human, Integrated, Evaluated (ARCHIE) model [92] (which emphasizes alignment of technology with social support and understanding of user requirements) and Nonadoption, Abandonment, Scale-Up, Spread, And 
Sustainability (NASSS) framework [93] (which claims that technology adoption requires cognitive participation of its users). The latter aspect has been often missed by some of older technology acceptance models, which have diminished the role of social constructs to a subjective perception [94]. Among the factors noted as a reason for technology non-adoption by older and/or ill people are the lack of social support (e.g., wearable activity trackers [95]), lack of usefulness (wearables and tablets [96]), or low practicality (e.g., mobile health apps [97]). On the other hand, the usefulness of equipment [98] have been explicitly outlined as one of the reasons for technology acceptance in the AAL domain.

\section{Discussion}

In this section, we discuss the outcomes of the review with respect to Research Questions outlined in Section 5.1. The following subsections each address the research questions formulated in Section 2.1.

\subsection{The Need for Machine Learning and Intelligent Decision Making and Control}

As we have shown in the current state-of-the-art analysis, the biggest part of current research and innovation activities in the area of smart homes and environments is still related with "traditional" automation via so called "smart" systems. A vast of such systems and technologies as well as commercial products are based on the predefined rules and pre-programmed sets of actions, which can be changed manually. This is not an efficient and convenient way of controlling smart environments since the environment conditions and the behavior and habits of the residents are constantly changing. The real "intelligence", or super-intelligence $[99,100]$, means not only simple automation (smart behavior), but also incorporates AI methods for observance, learning, adaptation, prediction and decision making, taking into account changing habits and behavior of the residents of the intelligent environment and the state of those residents and that environment.

Though AI is not a new concept, the application of AI in the area of smart homes and smart environments is still a challenge [101]. This is due to the very dynamic nature of smart environments as well as huge sets of hard real-time data generated by the residents and the environment itself [102]. On the other hand, the IoT technologies are good basis for distributed collection of data and controlling environment through various actuators and appliances.

\subsection{Situation on IoT Integration Technologies and Platforms}

The combination of AI and IoT opens new perspectives, allowing new kinds intelligent pervasive systems and platforms $[103,104]$, providing the highest level of comfort, energy savings or principally new personalized services for the inhabitants of intelligent environments. In contrast with usual automation solutions, such intelligent technologies would allow constant monitoring of the environment and its residents and learning from their behavior. Then this knowledge can be used to update environment control rules automatically, and even predict the future changes and events, providing services for the users without intervention (or with very minimal) from the latter. The currently proposed methods allow this partially, but still lack precision, fault tolerance, unobtrusiveness and stability like the system presented in [105].

\subsection{The Need for Methodologies and Tools for Multi-Agent Based Smart Applications for Assisted Living}

The main problem with today's IoT technologies, especially at the network and service level is the lack of common interoperability standards. There are a lot of initiatives and vendors, producing and fostering their own IoT solutions and devices/things using use different interoperability standards. However, these standards are not aligned and usually are not interoperable with each other [106,107]. This leads to the very fragmented IoT market, where users are forced to choose and use specific equipment from one producer with very limited ability directly combine different IoT platforms into one solution.

One of the fundamental paradigms related with intelligent IoT environments is multi-agent system [108]. Software agents usually are defined as autonomous data collection and decision-making 
software, which has at least some elements of AI. Each IoT device can have one or several agents, which are the "brains" of that thing and are able to communicate, interact and collaborate with each other. In such case intelligence and decision making is distributed across the whole IoT network leading to the so called collective or swarm intelligence. Moreover, agents can even travel across the IoT network (mobile agents).

In all cases the automated tools and technologies are needed for the deployment and monitoring of such multi-agent IoT based systems, adding additional management and services layer on the top of IoT hardware and middleware. Since IoT solutions are constructed of huge number of things/devices which should be deployed and programmed in some specific way, the IoT service providers and engineers need to have effective methodologies for the development of intelligent services, using computer aided development tools, which ideally do not require a technical knowledge about the underlying IoT or AI technologies.

\subsection{The Need for Cognitive and Affective IoT for Smart Home Environments}

The purpose is to re-establish an appropriate equilibrium between cognition and emotion in the development of IoT for smart home environments by considering user requirements to suit the needs, tastes and interests of aging people [109]. Cognitive and affective IoT for smart home environments are adaptive, interactive and contextual. Adaptive describes a system that can learn and adapt to diverse contexts without user involvement, since a home environment, user requests and needs fluctuate in real time. Interactive references a system that can interact with human, smart home services, tools and devices; the system can also ask a user questions, if a situation under analysis is still unclear.

A contextual system can recognize time, temperature, pollution, noise, human body language, requests and needs. For example, cognitive and affective IoT for smart home environments will provide personalized services for managing air quality and heating inside a building. Such context-aware systems are more likely to be well-received and accepted by its users. These will provide rational air quality (particulate matter, moisture, amount of oxygen etc.) and a rational temperature in each room and select the most suitable movie, music, lighting and the like for the comfort of its users in real time.

One of the major influences the IoT will possibly have in near future is a continuation of sensors-based marketing and retail. Some businesses are starting to apply the IoT for personalized sensors-based smart shopping, while provide assistive shopping services such as product finding and automated billing $[110,111]$. The most effective decision can be reached according to comprehensively descriptive demographic, educational, social, psychological, lifestyle, emotional, cultural, ethnic and other information about the users of this technology [112-115].

\subsection{The Need for Considering Psychosocial Factors of Human-Technology Interaction, Communication and Usage}

The impact of IoT-based gerontechnologies on social life can be various, depending on the actual design and features of the solution. Information technologies, including those based on internet adoption, allow older people to remain active longer [116] and maintain their social relationships [117]. Ambient intelligence enhanced with social networks and features can support independent living, social participation and online communication [118], as well as improve their health and contribute to better social well-being [119,120]. Unfortunately, ad hoc application of traditional system design methods may not always be considered as effective [121].

Tangible interface properties for the older people require abilities for intuitiveness, contextawareness, spatial interaction manipulation, and social interaction [122]. Authors of [123] suggest a Maslow hierarchy of human needs, displaying that users will be unlikely to assimilate IoT technologies which do not focus on their current needs and technology-oriented wellness parameters such as neurologically relevant kinematic parameters [124]. Whereas involving older people in the process of developing new gerontechnologies leads to a better acceptance and/or use of the innovative products [125]. According to [126], technology can make impact on affective quality, engagement, and connectedness of our behavior. A socio-technical study [127] suggests implementation of three 
relationships: community-technology, organization-technology, and individual-technology. These allow to successfully implement technology capable of appreciating the social implications of the technology.

In terms of willingness to use these technologies, older people might experience difficulties in accessing and using them, but growing and significant segments among older people are progressively more and more interested and willing to use technology, computers and even robotics. In many cases, older people could feel put aside from technology development [128]. For instance, a capability approach presented in [129] considers how technologies change the meaning of people abilities for social communication and engagement in relation with technical entities.

There are several socio-economic and psychological factors that can reinforce or limit the usage of technology by older people. In particular, the socio-economic profile is very relevant and associated with specific patterns of use. For instance, low educational level contributes to explain the low adoption of the ICT technologies by the older people (who had generally less educational opportunities in the past), including a perceived lack of necessity, even if relatively less reported than the functional literacy $[130,131]$. According to [132], age, gender and education have a significant influence on the overall usage of ICT. Therefore, the assistive IoT devices should adapt to individual needs to be able to address all these factors [133].

In terms of attitudes towards the IoT technology, older people usually rise some concerns about its use, including for instance privacy, trust and functionality. Other serious concerns are the cost of assistive technologies (the perception of whether the technology is actually 'worth buying'), ease of use, lack of training, fear of dependence and amortization barriers [134], and sensitive towards economic state of the older people [135]. In order to overcome possible perceived barriers, there are different complementary options that could optimize the technology adoption such as training and human tutoring [136]. More positive attitude of older people towards technology alternatives lead to increase likelihood of adoption of these smart technology products $[137,138]$. Furthermore, the findings of [139] indicate the importance of addressing older people's need for autonomy and their recognition of an aesthetic design [140].

Remote consultation, monitoring and care services provide a new opportunity for diagnostics, medical treatment, and rehabilitation, enabling clinicians to monitor at distance patients with chronic diseases and even multimorbidity [141]. These services increase greatly the possibility of access the healthcare system for people living in disadvantaged situations, including those with lower socio-economic status and from rural areas [142]. Medication pillbox solutions, like a medication self-management app (called ALICE) [143] and other solutions [144,145] can help to significantly reduce medication errors for older people with very little experience with ICT technologies.

\subsection{The Need for Localisation, Tracking and Human Activity Detection}

Many AAL applications need information about the position or movements of a human, or even extremities or hearts. The requirements for localization, tracking and activity detection systems can be manifold. Most important is that those systems must work in indoor environments such that many solutions, e.g., based on Global Positioning System (GPS), cannot be used [146]. Accuracy can range from centimeters, e.g., if movements of extremities shall be detected, to many meters, e.g., if it shall be detected whether a person is in a room. Usability is influenced by the fact whether the user must carry an additional device. Systems based on video monitoring can yield privacy issues. Deployment and operation costs depend on the coverage of a solution, i.e., whether sensors can detect positions in ranges of few meters or tens/hundreds of meters.

Systems providing position or movement information can be device-based or device-free. In case of device-based systems, humans carry a device transmitting or receiving some kind of optical (infrared, visible light), acoustic (ultrasound) or electromagnetic (WiFi, Bluetooth, Ultrawideband, Zigbee, cellular network signals, RFID) signals [147]. Those signals are then received, analyzed and processed by a central computing entity, so that the position or movement of the device can be determined. 
Active localization is based on the active participation of the device, which can measure signals from base stations or satellites (e.g., in GPS) and report back measurement results to a central system processing the measurements. This is often supported by a special software to be installed on the device. Passive localization does not require any changes in a device. Signals received by radio sensors are intercepted from regular data traffic exchanged between devices and base stations, e.g., cellular network base stations or WiFi access points.

Both active and passive localization are often based on determining the distance between a device and some sensors or base stations, which is also called ranging. Ranging mechanisms are based on measuring received signal strengths (RSS) or time (difference) of arrival [148]. Measured distances can then be fed into positioning algorithms such as multi-lateration or geometric algorithms [149]. Alternatively angles of arrival of the signals can be measured and processed, e.g., by using triangulation algorithms.

Activity detection can be based on tracking or just measuring the presence of a device. Device-free localization [150] does not require humans to carry a device. Cameras can detect persons. The position of the person can be detected by processing signals if the camera is moving or if there are multiple (stereo) cameras deployed.

Human localization and activity tracking is important for providing support for disabled (e.g., people with impaired vision of blind) or older people with mental problems (such as dementia or epilepsy). Such tracking requires the use of cognitive IoT technologies. In order to provide intelligent services and intelligent decision-making, the novel sensing technologies are needed. The existing environment and its residents monitoring methods still lack precision, require obtrusive sensing technologies, which are usually not comfortable for the wearer. The economic factor is also an issue, since installation of currently available systems is expensive, requiring many and complex hardware elements deployed at residents' homes. The users feel discomfort and their homes look more like a laboratory instead of a normal living environment. Again, as in the case with IoT based decision-making technologies, the IoT concept is very promising in the field of intelligent environment and users monitoring. Since each appliance or any "thing" at home can be part of IoT, it is a very convenient and unobtrusive way of collecting information about residents and environment's state, which later can be used for the intelligent decision making.

\subsection{Technological Potential}

Innovative and novel methods, technologies, services and products to improve the quality of life of inhabitants and users of intelligent AAL environments:

- Novel methods and technologies for very precise indoor positioning of older people or impaired inhabitants using wireless local area networks (WLAN) [151], Bluetooth beacons [152], radio and ultrasound signals.

- Innovative non-invasive and non-obtrusive methods for real-time human state and environment monitoring, posture identification while aiming for better precision, which can be implemented using standard/existing equipment and are much cheaper, less intrusive and more comfortable and affordable (e.g., using smartphone technology $[153,154])$

- Innovative personalized services and decision support systems [155] based on artificial intelligence (AI) methods aimed to o adapt to each home resident individually; to learn autonomously, without a priori information about the lifestyle and habits of the residents; to follow changing habits of residents and operate according to the resident's states and parameters of the environment; to make home control decisions without any additional intervention from the residents; and to provide a much higher level of comfort, safety and functionality, which cannot be achieved by any present technologies and methods.

- Novel development methodologies for the multi-agent intelligent AAL systems and services that allows the creation of dynamic, easily extended, and scalable solutions and do not require technical knowledge on the underlying technologies [156]. 
- Internet integration into relatively small devices, that could be integrated into currently still not computerized systems (e.g., household devices for smart house deployment and/or energy saving) or implanted into human body so as to increase mobility and quality of life of disabled people [157-159];

- Possibility for deployment of cheap geographically distributed and scalable network-centric infrastructure and middleware for AAL based on cloud computing and IoT (e.g., for monitoring passenger flows in transport, observing weather conditions for climate control, etc.) [160].

\section{Conclusions}

The use of AAL systems and platforms is increasing in line with the growing population of older people. Internet-of-Things (IoT) has emerged as a technological background for implementation of Ambient Assisted Living (AAL). Support for active and independent living requires addressing the main challenges of IoT such as data veracity, integration, interoperability, privacy, reliability, security, and usability.

Current study analyzed and discussed the following research issues of IoT-based technologies in AAL domain, focusing on how machine learning and intelligent decision making and control are used in IoT based AAL systems, how IoT integration technologies and platforms are employed for AAL solutions, what methodologies and tools are used for multi-agent based intellectual applications for assisted living, how ow cognitive and affective IoT is adopted for IoT based AAL systems, and what are the needs to consider psychosocial factors of human-technology interaction, communication and usage, and how localization, tracking and activity detection technologies are integrated into IoT based AAL systems.

This survey agrees with the previous surveys [161-163] in the AAL domain that more inter-disciplinary collaboration, human-oriented studies, and increased standardization is required to achieve more viable AAL implementations while employing the power of the future IoT [164].

The foreseen impacts of the implementation of IoT for AAL will target three specific societal issues:

- Digital transformation of public sector by implementing smart and personalized public e-services;

- Improved quality of life, work, leisure conditions and capabilities of the society members through application of innovative personalized intelligent products and services;

- Enhanced security and social isolation prevention.

The IoT technologies for AAL should also support economic development primarily in the short-to-medium period through tackling the following economic and societal issues:

- The need to foster knowledge- and technology-based economic development to support ageing population.

- The need to develop new markets for smart devices to diversify and increase sustainability of the digital economy that addresses the needs of active living and ageing.

- The need to encourage private investment in the smart IoT infrastructure for AAL.

To address and model these needs we have proposed the acceptance model of IoT-based gerontechnologies for the AAL domain, focusing primarily on the older users. The model summarizes the results of the review of the IoT technologies focusing on the acceptance and need of the adoption of IoT for the assistive living domain. Future work will include the validation of the model using a global survey of older people.

Author Contributions: Conceptualization, R.M. and S.S.; methodology, R.M. and S.S.; resources, R.M. and R.D.; writing-original draft preparation, R.M.; writing—review and editing, R.D.; visualization, R.D.; supervision, R.M.

Funding: This research received no external funding. 
Acknowledgments: Supported by CA COST Action CA15122-Reducing Old-Age Social Exclusion: Collaborations in Research and Policy (ROSEnet). Supported by IDO project-Innovative Digital Training Opportunities on Dementia for Direct Care Workers, co-funded by the Erasmus programme of the European Union, project-ID: 2017-1-SE01-KA202-034585.

Conflicts of Interest: The authors declare no conflict of interest.

\section{References}

1. Lopez, T.S.; Ranasinghe, D.C.; Harrison, M.; McFarlane, D. Adding sense to the internet of things. Pers. Ubiquit. Comput. 2012, 16, 291-308. [CrossRef]

2. Gigli, M.; Koo, S. Internet of Things: Services and Applications Categorization. J. Adv. Internet Things 2011, 1, 27-31. [CrossRef]

3. Ibarra-Esquer, J.E.; González-Navarro, F.F.; Flores-Rios, B.L.; Burtseva, L.; Astorga-Vargas, M.A. Tracking the Evolution of the Internet of Things Concept Across Different Application Domains. Sensors 2017, 17, 1379. [CrossRef] [PubMed]

4. Dang, L.M.; Piran, M.J.; Han, D.; Min, K.; Moon, H. A Survey on Internet of Things and Cloud Computing for Healthcare. Electronics 2019, 8, 768. [CrossRef]

5. Top Trends in the Gartner Hype Cycle for Emerging Technologies. 2017. Available online: https://www.gartner. com/smarterwithgartner/top-trends-in-the-gartner-hype-cycle-for-emerging-technologies-2017/ (accessed on 12 December 2019).

6. Demirkan, H.; Earley, S.; Harmon, R.R. Cognitive Computing. It Prof 2017, 19, 16-20. [CrossRef]

7. Chen, M.; Herrera, F.; Hwang, K. Cognitive Computing: Architecture, Technologies and Intelligent Applications. IEEE Access 2018, 6, 19774-19783. [CrossRef]

8. Wu, Q.; Ding, G.; Xu, Y.; Feng, S.; Du, Z.; Wang, J.; Long, K. Cognitive Internet of Things: A New Paradigm Beyond Connection. IEEE Internet Things J. 2014, 1, 129-143. [CrossRef]

9. Savage, R.; Yon, Y.; Campo, M.; Wilson, A.; Kahlon, R.; Sixsmith, A. Market Potential for Ambient Assisted Living Technology: The Case of Canada. Lect. Notes Comput. Sci. 2009, 57-65. [CrossRef]

10. Yusif, S.; Soar, J.; Hafeez-Baig, A. Older people, assistive technologies, and the barriers to adoption: A systematic review. Int. J. Med. Inf. 2016, 94, 112-116. [CrossRef]

11. Siegel, C.; Hochgatterer, A.; Dorner, T.E. Contributions of ambient assisted living for health and quality of life in the elderly and care services-A qualitative analysis from the experts' perspective of care service professionals. BMC Geriatr. 2014, 14, 112. [CrossRef]

12. Mulero, R.; Almeida, A.; Azkune, G.; Mainetti, L.; Mighali, V.; Patrono, L.; Rametta, P.; Sergi, I. An AAL system based on IoT technologies and linked open data for elderly monitoring in smart cities. In Proceedings of the 2nd International Multidisciplinary Conference on Computer and Energy Science (SpliTech), Split, Croatia, 12-14 July 2017; pp. 1-6.

13. Moreno, P.A.; Hernando, M.E.; Gómez, E.J. Design and Technical Evaluation of an Enhanced LocationAwareness Service Enabler for Spatial Disorientation Management of Elderly with Mild Cognitive Impairment. IEEE J. Biomed. Health Inform. 2015, 19, 37-43. [CrossRef] [PubMed]

14. Haufe, M.; Peek, S.T.M.; Luijkx, K.G. Matching gerontechnologies to independent-living seniors' individual needs: Development of the GTM tool. BMC Health Serv. Res. 2019, 19. [CrossRef] [PubMed]

15. Halicka, K. Gerontechnology-The assessment of one selected technology improving the quality of life of older adults. Eng. Manag. Prod. Serv. 2019, 11, 43-51. [CrossRef]

16. Blackman, S.; Matlo, C.; Bobrovitskiy, C.; Waldoch, A.; Fang, M.L.; Jackson, P.; Sixsmith, A. Ambient assisted living technologies for aging well: A scoping review. J. Intell. Syst. 2016, 25, 55-69. [CrossRef]

17. Kötteritzsch, A.; Weyers, B. Assistive technologies for older adults in urban areas: A literature review. Cogn. Comput. 2016, 8, 299-317. [CrossRef]

18. Peek, S.T.M.; Luijkx, K.G.; Rijnaard, M.D.; Nieboer, M.E.; Van Der Voort, C.S.; Aarts, S.; Wouters, E.J.M. Older adults' reasons for using technology while aging in place. Gerontology 2016, 62, 226-237. [CrossRef]

19. Le Deist, F.; Latouille, M. Acceptability conditions for telemonitoring gerontechnology in the elderly: Optimising the development and use of this new technology. IRBM 2016, 37, 284-288. [CrossRef]

20. Dietlein, C.; Eichberg, S.; Fleiner, T.; Zijlstra, W. Feasibility and effects of serious games for people with dementia: A systematic review and recommendations for future research. Gerontechnology 2018, 17, 1-17. [CrossRef] 
21. Sayago, S.; Rosales, A.; Righi, V.; Ferreira, S.M.; Coleman, G.W.; Blat, J. On the conceptualization, design, and evaluation of appealing, meaningful, and playable digital games for older people. Games Cult. 2016, 11, 53-80. [CrossRef]

22. Marcelino, I.; Laza, R.; Domingues, P.; Gómez-Meire, S.; Fdez-Riverola, F.; Pereira, A. Active and assisted living ecosystem for the elderly. Sensors 2018, 18, 1246. [CrossRef]

23. García-Valls, M.; Calva-Urrego, C.; García-Fornes, A. Accelerating smart eHealth services execution at the fog computing infrastructure. Future Gener. Comput. Syst. 2018. [CrossRef]

24. Kumari, A.; Tanwar, S.; Tyagi, S.; Kumar, N. Fog computing for Healthcare 4.0 environment: Opportunities and challenges. Comput. Electr. Eng. 2018, 72,1-13. [CrossRef]

25. Mutlag, A.A.; Ghani, M.K.A.; Arunkumar, N.; Mohamed, M.A.; Mohd, O. Enabling technologies for fog computing in healthcare IoT systems. Future Gener. Comput. Syst. 2019, 90, 62-78. [CrossRef]

26. Liu, L.; Stroulia, E.; Nikolaidis, I.; Miguel-Cruz, A.; Rios Rincon, A. Smart homes and home health monitoring technologies for older adults: A systematic review. Int. J. Med Inform. 2016, 91, 44-59. [CrossRef]

27. Islam, S.R.; Kwak, D.; Kabir, M.H.; Hossain, M.; Kwak, K.S. The internet of things for health care: A comprehensive survey. IEEE Access 2015, 3, 678-708. [CrossRef]

28. Farahani, B.; Firouzi, F.; Chang, V.; Badaroglu, M.; Constant, N.; Mankodiya, K. Towards fog-driven IoT eHealth: Promises and challenges of IoT in medicine and healthcare. Future Gener. Comput. Syst. 2018, 78, 659-676. [CrossRef]

29. Majumder, S.; Aghayi, E.; Noferesti, M.; Memarzadeh-Tehran, H.; Mondal, T.; Pang, Z.; Deen, M.J. Smart homes for elderly healthcare-Recent advances and research challenges. Sensors 2017, 17, 2496. [CrossRef]

30. Baker, S.B.; Xiang, W.; Atkinson, I. Internet of Things for Smart Healthcare: Technologies, Challenges, and Opportunities. IEEE Access 2017, 5, 26521-26544. [CrossRef]

31. Ahmadi, H.; Arji, G.; Shahmoradi, L.; Safdari, R.; Nilashi, M.; Alizadeh, M. The application of internet of things in healthcare: A systematic literature review and classification. Univer. Access Inf. Soc. 2018, 1-33. [CrossRef]

32. Kitchenham, B.A.; Charters, S.M. Guidelines for Performing Systematic Literature Reviews in Software Engineering; Technical Report EBSE-2007-01; School of Computer Science and Mathematics, Keele University: Keele, UK, 2007.

33. Petticrew, M.; Roberts, H. Systematic reviews in the social sciences: A practical guide. Eur. Psychol. 2008, 11, 244-245.

34. Moher, D.; Liberati, A.; Tetzlaff, J.; Altman, D.G. Preferred Reporting Items for Systematic Reviews and Meta-Analyses: The PRISMA Statement. PLoS Med. 2009, 6, e1000097. [CrossRef]

35. Byrne, C.; Collier, R.; O’Hare, G. A Review and Classification of Assisted Living Systems. Information 2018, 9, 182. [CrossRef]

36. Gubbi, J.; Buyya, R.; Marusic, S.; Palaniswami, M. Internet of Things (IoT): A vision, architectural elements, and future directions. Future Gener. Comput. Syst. 2013, 29, 1645-1660. [CrossRef]

37. Garcia, N.M.; Rodrigues, J.J.P.C. (Eds.) Ambient Assisted Living; CRC Press: Boca Raton, FL, USA, 2015. [CrossRef]

38. Li, J.; Wang, Y.; Lai, J.; Tan, H. Ambient assisted living. China Commun. 2016, 13, vi-vii. [CrossRef]

39. Suryadevara, N.K.; Mukhopadhyay, S.C. Determining Wellness through an Ambient Assisted Living Environment. IEEE Intell. Syst. 2014, 29, 30-37. [CrossRef]

40. Catarinucci, L.; de Donno, D.; Mainetti, L.; Palano, L.; Patrono, L.; Stefanizzi, M.L.; Tarricone, L. An IoT-Aware Architecture for Smart Healthcare Systems. IEEE Internet Things J. 2015, 2, 515-526. [CrossRef]

41. Calvaresi, D.; Cesarini, D.; Sernani, P.; Marinoni, M.; Dragoni, A.F.; Sturm, A. Exploring the ambient assisted living domain: A systematic review. J. Ambient Intell Hum. Comput 2016, 8, 239-257. [CrossRef]

42. Wang, D.; Lo, D.; Bhimani, J.; Sugiura, K. AnyControl-IoT Based Home Appliances Monitoring and Controlling. In Proceedings of the 2015 IEEE 39th Annual, Computer Software and Applications Conference (COMPSAC), Taichung, Taiwan, 1-5 July 2015; pp. 487-492. [CrossRef]

43. Perumal, T.; Datta, S.K.; Bonnet, C. IoT device management framework for smart home scenarios. In Proceedings of the 2015 IEEE 4th Global Conference on Consumer Electronics (GCCE), Osaka, Japan, 27-30 October 2015; pp. 54-55. [CrossRef]

44. Ghayvat, H.; Mukhopadhyay, S.; Gui, X.; Suryadevara, N. WSN- and IOT-Based Smart Homes and Their Extension to Smart Buildings. Sensors 2015, 15, 10350-10379. [CrossRef] 
45. Gračanin, D.; Matković, K.; Wheeler, J. An approach to modeling internet of things based smart built environments. In 2015 Winter Simulation Conference (WSC'15); IEEE Press: Piscataway, NJ, USA, 2015; pp. 3208-3209.

46. Beibei, T.; Yi, L. Upgraded Application of Intelligent Environment Monitoring System in IOT Smart Home. In Proceedings of the 2015 Sixth International Conference on Intelligent Systems Design and Engineering Applications (ISDEA), Guiyang, China, 18-19 August 2015; pp. 916-919. [CrossRef]

47. Konstantinidis, E.I.; Billis, A.; Savvidis, T.; Xefteris, S.; Bamidis, P.D. Emotion Recognition in the Wild: Results and Limitations from Active and Healthy Ageing cases in a Living Lab. In eHealth $360^{\circ}$; Giokas, K., Bokor, L., Hopfgartner, F., Eds.; Lecture Notes of the Institute for Computer Sciences, Social Informatics and Telecommunications Engineering; Springer: Cham, Switzerland, 2017; Volume 181.

48. Yoon, S.; Park, H.; Yoo, H.S. Security Issues on Smarthome in IoT Environment, Computer Science and its Applications. Ubiquitous Inf. Technol. 2015, 691-696. [CrossRef]

49. Chakrabarty, S.; Engels, D.W. A secure IoT architecture for Smart Cities. In Proceedings of the 2016 13th IEEE Annual Consumer Communications \& Networking Conference (CCNC), Las Vegas, NV, USA, 9-12 January 2016; pp. 812-813. [CrossRef]

50. Chianese, A.; Piccialli, F.; Valente, I. Smart environments and Cultural Heritage: A novel approach to create intelligent cultural spaces. J. Locat. Based Serv. 2015, 9, 209-234. [CrossRef]

51. Mighali, V.; Del Fiore, G.; Patrono, L.; Mainetti, L.; Alletto, S.; Serra, G.; Cucchiara, R. Innovative IoT-aware Services for a Smart Museum. In Proceedings of the 24th International Conference on World Wide Web (WWW'15 Companion), Florence, Italy, 18-22 May 2015; pp. 547-550. [CrossRef]

52. Lee, C.; Han, Y.; Jeon, S.; Seo, D.; Jung, I. Smart Parking System Using Ultrasonic Sensor and Bluetooth Communication in Internet of Things. Kiise Trans. Comput. Pract. 2016, 22, 268-277. [CrossRef]

53. Paredes, H.; Fernandes, H.; Sousa, A.; Fernandes, L.; Koch, F.; Fortes, R.; Filipe, V.; Barroso, J. Exploring Smart Environments Through Human Computation for Enhancing Blind Navigation. Adv. Soc. Comput. Multiagent Syst. 2015, 541, 66-76. [CrossRef]

54. Lopes, N.V.; Santos, H.; Azevedo, A.I. Detection of Dangerous Situations Using a Smart Internet of Things System. In New Contributions in Information Systems and Technologies; Springer: Berlin, Germany, 2015; Volume 354, pp. 387-396. [CrossRef]

55. Kim, B.; Kang, S.; Ha, J.-Y.; Song, J. Agatha: Predicting Daily Activities from Place Visit History for Activity-Aware Mobile Services in Smart Cities. Int. J. Distrib. Sens. Netw. 2015, 11, 867602. [CrossRef]

56. Pires, P.; Mendes, L.; Mendes, J.; Rodrigues, R.; Pereira, A. Integrated e-healthcare system for elderly support. Cogn. Comput. 2016, 8, 368-384. [CrossRef]

57. Park, H.; Kim, H.; Joo, H.; Song, J. Recent advancements in the Internet-of-Things related standards: A oneM2M perspective. ICT Express 2016, 2, 126-129. [CrossRef]

58. Kolias, C.; Kambourakis, G.; Stavrou, A.; Voas, J. DDoS in the IoT: Mirai and Other Botnets. Computer 2017, 50, 80-84. [CrossRef]

59. De Donno, M.; Dragoni, N.; Giaretta, A.; Spognardi, A. DDoS-Capable IoT Malwares: Comparative Analysis and Mirai Investigation. Secur. Commun. Netw. 2018, 1-30. [CrossRef]

60. Tarouco, L.M.R.; Bertholdo, L.M.; Granville, L.Z.; Arbiza, L.M.R.; Carbone, F.; Marotta, M.; de Santanna, J.J.C. Internet of Things in healthcare: Interoperatibility and security issues. In Proceedings of the 2012 IEEE International Conference on Communications (ICC), Ottawa, ON, Canada, 10-15 June 2012; pp. 6121-6125. [CrossRef]

61. Riahi, A.; Challal, Y.; Natalizio, E.; Chtourou, Z.; Bouabdallah, A. A Systemic Approach for IoT Security. In Proceedings of the 2013 IEEE International Conference on Distributed Computing in Sensor Systems, Cambridge, MA, USA, 20-23 May 2013; pp. 351-355. [CrossRef]

62. Roman, R.; Zhou, J.; Lopez, J. On the features and challenges of security and privacy in distributed internet of things. Comput. Netw. 2013, 57, 2266-2279. [CrossRef]

63. Ukil, A.; Sen, J.; Koilakonda, S. Embedded security for Internet of Things. In Proceedings of the 2nd National Conference on Emerging Trends and Applications in Computer Science, Shillong, India, 4-5 March 2011; pp. 1-6. [CrossRef]

64. Brachmann, M.; Keoh, S.L.; Morchon, O.G.; Kumar, S.S. End-to-End Transport Security in the IP-Based Internet of Things. In Proceedings of the 21st International Conference on Computer Communications and Networks (ICCCN), Munich, Germany, 30 July-2 August 2012; pp. 1-5. [CrossRef] 
65. Abomhara, M.; Køien, G.M. Security and privacy in the Internet of Things: Current status and open issues. In Proceedings of the International Conference on Privacy and Security in Mobile Systems (PRISMS), Aalborg, Denmark, 11-14 May 2014; pp. 1-8. [CrossRef]

66. Jing, Q.; Vasilakos, A.V.; Wan, J.; Lu, J.; Qiu, D. Security of the Internet of Things: Perspectives and challenges. Wirel. Netw 2014, 20, 2481. [CrossRef]

67. Venčkauskas, A.; Morkevicius, N.; Jukavičius, V.; Damaševičius, R.; Toldinas, J.; Grigaliūnas, Š. An Edge-Fog Secure Self-Authenticable Data Transfer Protocol. Sensors 2019, 19, 3612. [CrossRef]

68. Villari, M.; Al-Anbuky, A.; Celesti, A.; Moessner, K. Leveraging the Internet of Things: Integration of Sensors and Cloud Computing Systems. Int. J. Distrib. Sens. Netw. 2016, 12, 9764287. [CrossRef]

69. Hao, A.; Wang, L. Medical Device Integration Model Based on the Internet of Things. Open Biomed. Eng. J. 2015, 9, 256-261. [CrossRef] [PubMed]

70. Van Duijnhoven, J.; Aarts, M.P.J.; Kort, H.S.M.; Rosemann, A.L.P. External validations of a non-obtrusive practical method to measure personal lighting conditions in offices. Build. Environ. 2018, 134, 74-86. [CrossRef]

71. Ng, I.C.L.; Wakenshaw, S.Y.L. The Internet-of-Things: Review and research directions. Int. J. Res. Mark. 2017, 34, 3-21. [CrossRef]

72. Ando, B.; Siciliano, P.; Marletta, V.; Monteriù, A. (Eds.) Ambient Assisted Living; Springer: Cham, Switzerland, 2015. [CrossRef]

73. Davis, F.D. Perceived Usefulness, Perceived Ease of Use, and User Acceptance of lnformation Technology. MIS Q. 1989, 13, 319-340. [CrossRef]

74. Chen, K.; Chan, A.H. Gerontechnology acceptance by elderly Hong Kong Chinese: A senior technology acceptance model (STAM). Ergonomics 2014, 57, 635-652. [CrossRef]

75. Jia, P.; Lu, Y.; Wajda, B. Designing for Technology Acceptance in an Ageing Society through Multi-stakeholder Collaboration. Procedia Manuf. 2015, 3, 3535-3542. [CrossRef]

76. Joseph, S.; Teh, P.; Chan, A.H.S.; Ahmed, P.K.; Cheong, S.; Yap, W. Gerontechnology usage and acceptance model (GUAM): A qualitative study of chinese older adults in malaysia. Gerontechnology 2016, 14, 224-238. [CrossRef]

77. Strough, J.; de Bruin, W.B.; Peters, E. New perspectives for motivating better decisions in older adults. Front. Psychol. 2015, 6, 783. [CrossRef]

78. Wu, Y.; Damnée, S.; Kerhervé, H.; Ware, C.; Rigaud, A. Bridging the digital divide in older adults: A study from an initiative to inform older adults about new technologies. Clin. Interv. Aging 2015, 10, 193-201. [CrossRef]

79. Guo, X.; Shen, Z.; Zhang, Y.; Wu, T. Review on the Application of Artificial Intelligence in Smart Homes. Smart Cities 2019, 2, 402-420. [CrossRef]

80. Conte, S.; Munteanu, C. An Interactive Tactile Aid for Older Adults Learning to Use Tablet Devices. In Proceedings of the Extended Abstracts of the $2018 \mathrm{CHI}$ Conference on Human Factors in Computing Systems-CHI'18, Montreal, QC, Canada, 21-26 April 2018. [CrossRef]

81. Mi, X.; Qian, F.; Zhang, Y.; Wang, X. An empirical characterization of IFTTT. In Proceedings of the 2017 Internet Measurement Conference on-IMC'17, London, UK, 1-3 November 2017. [CrossRef]

82. Simonnet, M.; Gourvennec, B. Heart rate sensors acceptability: Data reliability vs. ease of use. In Proceedings of the 2016 IEEE 13th International Conference on Wearable and Implantable Body Sensor Networks (BSN), San Francisco, CA, USA, 14-17 June 2016. [CrossRef]

83. Higuera, J.; Llenas, A.; Carreras, J. Trends in smart lighting for the Internet of Things. arXiv 2018, arXiv:1809.00986.

84. Minatani, K. Smart Apps vs. Renovated Low-tech Devices with DIY Assistive Technology: A Case of a Banknote Identifier for Visually Impaired People. In Proceedings of the 5th EAI International Conference on Smart Objects and Technologies for Social Good (GoodTechs'19), Valencia, Spain, 25-27 September 2019; pp. 96-101. [CrossRef]

85. Chou, Y.S.; Chen, D.F. Research on the Combination of IoT and Assistive Technology Device-Prosthetic Damping Control as an Example. In Frontier Computing. FC 2018; Hung, J., Yen, N., Hui, L., Eds.; Lecture Notes in Electrical Engineering; Springer: Singapore, 2019; Volume 542, pp. 1934-1938.

86. Molenbroek, J.F.M.; Mantas, J.; De Bruin, R. (Eds.) A Friendly Rest Room: Developing Toilets of the Future for Disabled and Elderly People; IOS Press: Amsterdam, The Netherlands, 2011. 
87. Mulfari, D.; Minnolo, A.L.; Puliafito, A. Wearable Devices and IoT as Enablers of Assistive Technologies. In Proceedings of the 2017 10th International Conference on Developments in eSystems Engineering (DeSE), Paris, France, 14-16 June 2017. [CrossRef]

88. Borelli, E.; Paolini, G.; Antoniazzi, F.; Barbiroli, M.; Benassi, F.; Chesani, F.; Chiari, L.; Fantini, M.; Fuschini, F.; Galassi, A.; et al. HABITAT: An IoT Solution for Independent Elderly. Sensors 2019, 19, 1258. [CrossRef] [PubMed]

89. Monteriù, A.; Prist, M.R.; Frontoni, E.; Longhi, S.; Pietroni, F.; Casaccia, S.; Scalise, L.; Cenci, A.; Romeo, L.; Berta, R.; et al. A Smart Sensing Architecture for Domestic Monitoring: Methodological Approach and Experimental Validation. Sensors 2018, 18, 2310. [CrossRef] [PubMed]

90. Ngueleu, A.M.; Blanchette, A.K.; Maltais, D.; Moffet, H.; McFadyen, B.J.; Bouyer, L.; Batcho, C.S. Validity of Instrumented Insoles for Step Counting, Posture and Activity Recognition: A Systematic Review. Sensors 2019, 19, 2438. [CrossRef] [PubMed]

91. Hergenroeder, A.L.; Gibbs, B.B.; Kotlarczyk, M.P.; Perera, S.; Brach, J.S.; Kowalsky, R.J. Accuracy and Acceptability of Commercial Grade Physical Activity Monitors in Older Adults. J. Aging Phys. Act. 2019, 27, 222-229. [CrossRef] [PubMed]

92. Greenhalgh, T.; Procter, R.; Wherton, J.; Sugarhood, P.; Hinder, S.; Rouncefield, M. What is quality in assisted living technology? The ARCHIE framework for effective telehealth and telecare services. BMC Med. 2015, 13, 91. [CrossRef] [PubMed]

93. Greenhalgh, T.; Wherton, J.; Papoutsi, C.; Lynch, J.; Hughes, G.; A'Court, C.; Shaw, S. Beyond Adoption: A New Framework for Theorizing and Evaluating Nonadoption, Abandonment, and Challenges to the Scale-Up, Spread, and Sustainability of Health and Care Technologies. J. Med. Internet Res. 2017, 19, e367. [CrossRef]

94. Venkatesh, V.; Morris, M.; Davis, G.; Davis, F. User acceptance of information technology: Toward a unified view. Manag. Inf. Syst. Q. 2003, 27, 425-478. [CrossRef]

95. Kononova, A.; Li, L.; Kamp, K.; Bowen, M.; Rikard, R.V.; Cotten, S.; Peng, W. The use of wearable activity trackers among older adults: Focus group study of tracker perceptions, motivators, and barriers in the maintenance stage of behavior change. J. Med. Internet Res. 2019, 21. [CrossRef]

96. Bryson, D. The adoption and nonadoption of new technologies by the active ageing. Textile-Led Des. Act. Ageing Popul. 2015, 47-58. [CrossRef]

97. Valdez, A.C.; Ziefle, M. Older users' rejection of mobile health apps a case for a stand-alone device? In Lecture Notes in Computer Science; Springer International Publishing: Cham, Switzerland, 2015; pp. 38-49. [CrossRef]

98. Cook, E.J.; Randhawa, G.; Sharp, C.; Ali, N.; Guppy, A.; Barton, G.; Crawford-White, J. Exploring the factors that influence the decision to adopt and engage with an integrated assistive telehealth and telecare service in Cambridgeshire, UK: A nested qualitative study of patient "users" and "non-users". BMC Health Serv. Res. 2016, 16. [CrossRef] [PubMed]

99. Gill, K.S. Artificial super intelligence: Beyond rhetoric. AI Soc. 2016, 31, 137-143. [CrossRef]

100. Wogu, I.A.P.; Misra, S.; Assibong, P.A.; Ogiri, S.O.; Damasevicius, R.; Maskeliunas, R. Super-Intelligent Machine Operations in Twenty-First-Century Manufacturing Industries: A Boost or Doom to Political and Human Development? In Towards Extensible and Adaptable Methods in Computing; Springer: Singapore, 2018; pp. 209-224. [CrossRef]

101. Romaniuk, R.S. IoT-Review of critical issues. Int. J. Electron. Telecommun. 2018, 64, 95-102. [CrossRef]

102. Sun, H.; de Florio, V.; Gui, N.; Blondia, C. Towards building virtual community for ambient assisted living. In Proceedings of the 16th Euromicro Conference on Parallel, Distributed and Network-Based Processing (PDP'08), Toulouse, France, 13-15 February 2008; pp. 556-561.

103. Ajami, H.; Mcheick, H.; Mustapha, K. A Pervasive Healthcare System for COPD Patients. Diagnostics 2019, 9, 135. [CrossRef]

104. Rubí, J.N.S.; Gondim, P.R.L. IoMT Platform for Pervasive Healthcare Data Aggregation, Processing, and Sharing Based on OneM2M and OpenEHR. Sensors 2019, 19, 4283. [CrossRef]

105. Cole, R.J.; Brown, Z. Reconciling human and automated intelligence in the provision of occupant comfort. Intell. Build. Int. 2009, 1, 39-55. [CrossRef]

106. Karpenko, A.; Kinnunen, T.; Madhikermi, M.; Robert, J.; Främling, K.; Dave, B.; Nurminen, A. Data Exchange Interoperability in IoT Ecosystem for Smart Parking and EV Charging. Sensors 2018, 18, 4404. [CrossRef] 
107. Peng, C.; Goswami, P. Meaningful Integration of Data from Heterogeneous Health Services and Home Environment Based on Ontology. Sensors 2019, 19, 1747. [CrossRef]

108. Savaglio, C.; Fortino, G.; Ganzha, M.; Paprzycki, M.; Bădică, C.; Ivanović, M. Agent-Based Computing in the Internet of Things: A Survey. In Intelligent Distributed Computing XI; Springer International Publishing: Cham, Switzerland, 2017; pp. 307-320. [CrossRef]

109. Castillo, J.C.; Castro-González, Á.; Fernández-Caballero, A.; Latorre, J.M.; Pastor, J.M.; Fernández-Sotos, A.; Salichs, M.A. Software architecture for smart emotion recognition and regulation of the ageing adult. Cogn. Comput. 2016, 8, 357-367. [CrossRef]

110. Chiang, H.-H.; You, W.-T.; Lin, S.-H.; Shih, W.-C.; Liao, Y.-T.; Lee, J.-S.; Chen, Y.-L. Development of smart shopping carts with customer-oriented service. In Proceedings of the 2016 International Conference on System Science and Engineering (ICSSE), Puli, Taiwan, 7-9 July 2016. [CrossRef]

111. Wang, Y.-C.; Yang, C.-C. 3S-cart: A Lightweight, Interactive Sensor-Based Cart for Smart Shopping in Supermarkets. IEEE Sens. J. 2016, 16, 6774-6781. [CrossRef]

112. Chen, M.; Yang, J.; Zhu, X.; Wang, X.; Liu, M.; Song, J. Smart home 2.0: Innovative smart home system powered by botanical IoT and emotion detection. Mob. Netw. Appl. 2017, 22, 1159-1169. [CrossRef]

113. Ricci, A.; Piunti, M.; Tummolini, L.; Castelfranchi, C. The Mirror World: Preparing for Mixed-Reality Living. IEEE Pervasive Comput. 2015, 14, 60-63. [CrossRef]

114. Modoni, G.E.; Veniero, M.; Trombetta, A.; Sacco, M.; Clemente, S. Semantic based events signaling for AAL systems. J. Ambient Intell. Humaniz. Comput. 2018, 9, 1311-1325. [CrossRef]

115. Costa, A.; Rincon, J.A.; Carrascosa, C.; Julian, V.; Novais, P. Emotions detection on an ambient intelligent system using wearable devices. Future Gener. Comput. Syst. 2019, 92, 479-489. [CrossRef]

116. Niehaves, B.; Plattfaut, R. Internet adoption by the elderly: Employing IS technology acceptance theories for understanding the age-related digital divide. Eur. J. Inf. Syst. 2014, 23, 708. [CrossRef]

117. Chaumon, M.-E.B.; Michel, C.; Tarpin Bernard, F.; Croisile, B. Can ICT improve the quality of life of elderly adults living in residential home care units? From actual impacts to hidden artefacts. Behav. Inf. Technol. 2014, 33. [CrossRef]

118. Doppler, J.; Sommer, S.; Gradl, C.; Rottermanner, G. BRELOMATE-A Distributed, Multi-device Platform for Online Information, Communication and Gaming Services Among the Elderly. In Computers Helping People with Special Needs; Miesenberger, K., Bühler, C., Penaz, P., Eds.; ICCHP 2016; Lecture Notes in Computer Science; Springer: Cham, Switzerland, 2016; Volume 9758.

119. Campos, W.; Martinez, A.; Sanchez, W.; Estrada, H.; Castro-Sánchez, N.A.; Mujica, D. A Systematic Review of Proposals for the Social Integration of Elderly People Using Ambient Intelligence and Social Networking Sites. Cogn. Comput. 2016, 8, 529. [CrossRef]

120. Sharma, D.; Blair, L.; Clune, S. Developing Radical-Digital Interventions to Tackle Loneliness Amongst the Elderly. In Human Aspects of IT for the Aged Population; Zhou, J., Salvendy, G., Eds.; Design for Everyday Life. ITAP 2015; Lecture Notes in Computer Science; Springer: Cham, Switzerland, 2015; Volume 9194.

121. Silva, S. Developing technologies for the elderly: To whom are we really developing? In Proceedings of the 2015 37th Annual International Conference of the IEEE Engineering in Medicine and Biology Society (EMBC), Milan, Italy, 25-29 August 2015; pp. 8030-8033. [CrossRef]

122. Cho, M.E.; Kim, M.J.; Kim, J.T. Design principles of user interfaces for the elderly in health smart homes. In Proceedings of the 10th International Symposium on Sustainable Healthy Buildings, Seoul, Korea, 7 June 2013.

123. Thielke, S.; Harniss, M.; Thompson, H.; Patel, S.; Demiris, G.; Johnson, K. Maslow's Hierarchy of Human Needs and the Adoption of Health-Related Technologies for Older Adults. Ageing Int 2012, 37, 470. [CrossRef]

124. Morgavi, G.; Nerino, R.; Marconi, L.; Cutugno, P.; Ferraris, C.; Cinini, A.; Morando, M. An Integrated Approach to the Well-Being of the Elderly People at Home. In Ambient Assisted Living. Biosystems E Biorobotics; Andò, B., Siciliano, P., Marletta, V., Monteriù, A., Eds.; Springer: Cham, Switzerland, 2015; Volume 11.

125. Merkel, S.; Kucharski, A. Participatory design in gerontechnology: A systematic literature review. Gerontologist 2019, 59, E16-E25. [CrossRef]

126. Riva, G.; Baños, R.M.; Botella, C.; Wiederhold, B.K.; Gaggioli, A. Positive Technology: Using Interactive Technologies to Promote Positive Functioning. Cyberpsychol. Behav. Soc. Netw. 2012, 15, 69-77. [CrossRef] [PubMed] 
127. Kolkowska, E.; Avatare Nöu, A.; Sjölinder, M.; Scandurra, I. Socio-Technical Challenges in Implementation of Monitoring Technologies in Elderly Care. In Human Aspects of IT for the Aged Population. Healthy and Active Aging. ITAP 2016; Zhou, J., Salvendy, G., Eds.; Lecture Notes in Computer Science; Springer: Cham, Switzerland, 2016; Volume 9755.

128. Reppou, S.; Karagiannis, G. Social Inclusion with Robots: A RAPP Case Study Using NAO for Technology Illiterate Elderly at Ormylia Foundation. In Progress in Automation, Robotics and Measuring Techniques; Szewczyk, R., Zieliński, C., Kaliczyńska, M., Eds.; Advances in Intelligent Systems and Computing; Springer: Berlin, Germany, 2015; Volume 351.

129. Coeckelbergh, M. How I Learned to Love the Robot: Capabilities, Information Technologies, and Elderly Care. In The Capability Approach, Technology and Design. Philosophy of Engineering and Technology; Oosterlaken, I., van den Hoven, J., Eds.; Springer: Dordrecht, The Netherlands, 2012; Volume 5.

130. Neves, B.; Amaro, F. Too Old for Technology? How the Elderly of Lisbon Use and Perceive ICT. J. Community Inform. 2012, 8, 12.

131. Simonova, I.; Poulova, P. Level of Education and Previous Experience in Acquiring ICT/Smart Technologies by the Elderly People. In Intelligent Information and Database Systems. ACIIDS 2017; Nguyen, N., Tojo, S., Nguyen, L., Trawiński, B., Eds.; Lecture Notes in Computer Science; Springer: Cham, Switzerland, 2017; Volume 10191.

132. Ramón-Jerónimo, M.A.; Peral-Peral, B.; Arenas-Gaitán, J. Elderly Persons and Internet Use. Soc. Sci. Comput. Rev. 2013, 31, 389-403. [CrossRef]

133. Flandorfer, P. Population Ageing and Socially Assistive Robots for Elderly Persons: The Importance of Sociodemographic Factors for User Acceptance. Int. J. Popul. Res. 2012, 2012, 13. [CrossRef]

134. Mertens, A.W.; Wille, M.; Theis, S.; Rasche, P.; Finken, L.; Schlick, C.M. Attitudes of Elderly People towards Assistive System: Influence of Amortization Barriers on the Adherence in Technically Assisted Rehabilitation and the Diffusion of Health Technologies. In Proceedings of the 19th Triennial Congress of the IEA, Melbourne, Australia, 9-14 August 2015; Volume 9, p. 14.

135. Sharma, R.; Nah, F.F.H.; Sharma, K.; Katta, T.S.S.S.; Pang, N.; Yong, A. Smart Living for Elderly: Design and Human-Computer Interaction Considerations. In Human Aspects of IT for the Aged Population. Healthy and Active Aging. ITAP 2016; Zhou, J., Salvendy, G., Eds.; Lecture Notes in Computer Science; Springer: Cham, Switzerland, 2016; Volume 9755.

136. Kumar, S.; Wallace, C. Patterns of inquiry in computer literacy help sessions for the elderly. In Proceedings of the 6th International Conference on PErvasive Technologies Related to Assistive Environments, PETRA'13, Article No. 54, Rhodes, Greece, 29-31 May 2013.

137. Golant, S.M. A theoretical model to explain the smart technology adoption behaviors of elder consumers (elderadopt). J. Aging Stud. 2017, 42, 56-73. [CrossRef]

138. Lesauskaitè, V.; Damulevičienė, G.; Knašienè, J.; Kazanavičius, E.; Liutkevičius, A.; Janavičiūtè, A. Older adults-Potential users of technologies. Medicina (Kaunas) 2019, 55. [CrossRef]

139. Sas, C.; Brahney, K.; Oechsner, C.; Trivedi, A.; Nomesque, M.; Mughal, Z.; Cheverst, K.W.J.; Clinch, S.E.; Davies, N.A.J. Communication Needs of Elderly at Risk of Falls and their Remote Family. In Proceedings of the 2017 CHI Conference Extended Abstracts on Human Factors in Computing Systems, CHI EA'17, Denver, CO, USA, 6-11 May 2017; pp. 2900-2908, ISBN 9781450346566.

140. Hornung, D.; Müller, C.; Boden, A.; Stein, M. Autonomy Support for Elderly People through Everyday Life Gadgets. In Proceedings of the 19th International Conference on Supporting Group Work, GROUP'16, Sanibel Island, FL, USA, 13-16 November 2016; pp. 421-424.

141. Barbabella, F.; Melchiorre, M.G.; Quattrini, S.; Papa, R.; Lamura, G. How can eHealth improve care for people with multimorbidity in Europe? Health Syst. Policy Anal. Policy Brief 2017, 25, 1-31.

142. Bujnowska-Fedak, M.; Grata-Borkowska, U. Use of telemedicine-based care for the aging and elderly: Promises and pitfalls. Smart Homecare Technol. Telehealth 2015, 91. [CrossRef]

143. Mira, J.J.; Navarro, I.; Botella, F.; Borrás, F.; Nuño-Solinís, R.; Orozco, D.; Toro, N. A Spanish Pillbox App for Elderly Patients Taking Multiple Medications: Randomized Controlled Trial. J. Med. Internet Res. 2014, 16, e99. [CrossRef]

144. Tsai, H.-L.; Tseng, C.H.; Wang, L.-C.; Juang, F.-S. Bidirectional smart pill box monitored through internet and receiving reminding message from remote relatives. In Proceedings of the 2017 IEEE International Conference on Consumer Electronics-Taiwan (ICCE-TW), Taipei, Taiwan, 12-14 June 2017. [CrossRef] 
145. Minaam, D.S.A.; Abd-ELfattah, M. Smart drugs: Improving healthcare using Smart Pill Box for Medicine Reminder and Monitoring System. Future Comput. Inform. J. 2018, 3, 443-456. [CrossRef]

146. Mautz, R. Indoor Positioning Technologies. Habilitation Thesis, ETH Zürich, Zürich, Switzerland, 2012. [CrossRef]

147. Liu, H.; Darabi, H.; Banerjee, P.; Liu, J. Survey of Wireless Indoor Positioning Techniques and Systems. IEEE Trans. Syst. Man Cybern. Part. C Appl. Rev. 2007, 37, 1067-1080. [CrossRef]

148. Farid, Z.; Nordin, R.; Ismail, M. Recent Advances in Wireless Indoor Localization Techniques and System. J. Comput. Netw. Commun. 2013, 2013, 12. [CrossRef]

149. Alyafawi, I.; Dimitrova, D.C.; Braun, T. SDR-based passive indoor localization system for GSM. In Proceedings of the 2014 ACM Workshop on Software Radio Implementation Forum (SRIF'14), Chicago, IL, USA, 18 August 2014; pp. 7-14. [CrossRef]

150. Pirzada, N.; Nayan, M.Y.; Hassan, F.S.M.F.; Khan, M.A. Device-free Localization Technique for Indoor Detection and Tracking of Human Body: A Survey. Procedia Soc. Behav. Sci. 2014, 129, 422-429. [CrossRef]

151. Orujov, F.; Maskeliūnas, R.; Damaševičius, R.; Wei, W.; Li, Y. Smartphone based intelligent indoor positioning using fuzzy logic. Future Gener. Comput. Syst. 2018, 89, 335-348. [CrossRef]

152. AL-Madani, B.; Orujov, F.; Maskeliūnas, R.; Damaševičius, R.; Venčkauskas, A. Fuzzy Logic Type-2 Based Wireless Indoor Localization System for Navigation of Visually Impaired People in Buildings. Sensors 2019, 19, 2114. [CrossRef] [PubMed]

153. Damaševičius, R.; Vasiljevas, M.; Šalkevičius, J.; Woźniak, M. Human Activity Recognition in AAL Environments Using Random Projections. Comput. Math. Methods Med. 2016, 1-17. [CrossRef] [PubMed]

154. Rizzuto, M.A.; Sonne, M.W.L.; Vignais, N.; Keir, P.J. Evaluation of a virtual reality head mounted display as a tool for posture assessment in digital human modelling software. Appl. Ergon. 2019, 79, 1-8. [CrossRef]

155. Russell, L.; Goubran, R.; Kwamena, F. Personalization Using Sensors for Preliminary Human Detection in an IoT Environment. In Proceedings of the 2015 International Conference on Distributed Computing in Sensor Systems, Fortaleza, Brazil, 10-12 June 2015; pp. 236-241. [CrossRef]

156. Zouai, M.; Kazar, O.; Haba, B.; Saouli, H. Smart house simulation based multi-agent system and internet of things. In Proceedings of the 2017 International Conference on Mathematics and Information Technology (ICMIT), Adrar, Algeria, 4-5 December 2017; pp. 201-203. [CrossRef]

157. Haddow, G.; Harmon, S.H.; Gilman, L. Implantable Smart Technologies (IST): Defining the 'Sting' in Data and Device. J. Health Philos. Policy 2016, 24, 210-227. [CrossRef]

158. Guida, R.; Melodia, T. Ultrasonically Rechargeable Platforms for Closed-Loop Distributed Sensing and Actuation in the Human Body. In Proceedings of the 2018 IEEE 19th International Workshop on Signal Processing Advances in Wireless Communications (SPAWC), Kalamata, Greece, 25-28 June 2018; pp. 1-5. [CrossRef]

159. Al-khafajiy, M.; Baker, T.; Chalmers, C.; Asim, M.; Kolivand, H.; Fahim, M.; Waraich, A. Remote health monitoring of elderly through wearable sensors. Multimed. Tools Appl. 2019, 78, 24681-24706. [CrossRef]

160. Gomes, B.d.T.P.; Muniz, L.C.M.; da Silva e Silva, F.J.; Ríos, L.E.T.; Endler, M. A comprehensive and scalable middleware for Ambient Assisted Living based on cloud computing and Internet of Things. Concurr. Comput. Pract. Exp. 2016, 29, e4043. [CrossRef]

161. Memon, M.; Wagner, S.R.; Pedersen, C.F.; Beevi, F.H.A.; Hansen, F.O. Ambient Assisted Living Healthcare Frameworks, Platforms, Standards, and Quality Attributes. Sensors 2014, 14, 4312-4341. [CrossRef] [PubMed]

162. Duarte, P.A.S.; Barreto, F.M.; Aguilar, P.A.C.; Boudy, J.; Andrade, R.M.C.; Viana, W. AAL Platforms Challenges in IoT Era: A Tertiary Study. In Proceedings of the 13th Annual Conference on System of Systems Engineering (SoSE), Paris, France, 19-22 June 2018; pp. 106-113. [CrossRef]

163. Marques, G.; Pitarma, R.M.; Garcia, N.; Pombo, N. Internet of Things Architectures, Technologies, Applications, Challenges, and Future Directions for Enhanced Living Environments and Healthcare Systems: A Review. Electronics 2019, 8, 1081. [CrossRef]

164. Cirillo, F.; Wu, F.-J.; Solmaz, G.; Kovacs, E. Embracing the Future Internet of Things. Sensors 2019, $19,351$. [CrossRef] [PubMed]

(C) 2019 by the authors. Licensee MDPI, Basel, Switzerland. This article is an open access article distributed under the terms and conditions of the Creative Commons Attribution (CC BY) license (http://creativecommons.org/licenses/by/4.0/). 